\title{
Saskatchewan Tortoise Shell Butterflies
}

\author{
DONALD HOOPER, SOMME, SASK.
}

There are four species of Tortoise-shells found in North America. My brother and I have taken specimens of each in the Somme district. They can be easily recognized by the accompanying photographs. The butterflies that most closely resemble the Tortoise-shells are the Angel-wings which can be distinguished by the concave shape of the inner margin of the forewing. This is straight in the Tortoise-shells. All Tortoise-shells hibernate as adults and thus are our first spring butterflies. They are as follows:

\section{MOURNING CLOAK Nymphalis antiopa}

This is a fairly common species throughout the province. It is found mostly in open woods and scrubland. The butterfly is blackish brown with a broad yellow border. Inside the yellow border is a row of blue spots. It has a wing expanse of about three inches.

The caterpillars are quite hairy. They are black in color with red spots down the back. They feed on elm, willow, poplar and rose. We have found caterpillars on Salix discolor.

\section{MILBERT'S or AMERICAN TORTOISE-SHELL \\ Nymphalis milberti}

This is a very pretty little insect, commonly found throughout the province. The color is dark with a yellow-orange submarginal band. The wing span is $13 / 4$ inches. This is generally our first spring butterfly, coming about the first week in April.

The larvae feed on nettle and therefore is mostly found in farm yards and waste places.

\section{COMPTON TORTOISE-SHELL} Nymphalis j-album

This species is found Iocally in mixed forest, straying into adjacent farm lands on windy days in late fall. They have the habit of landing on the walls of buildings, or flying about the eaves. They often hibernate in deserted houses.

This butterfly is beautifully mottled with black, brown, orange, yellow and white. On the underside of the wings is brownish gray, with a white " $j$ " on the hind wing. It has a wing span of $21 / 2$ inches. The caterpillars feed on birch, poplar and willows.
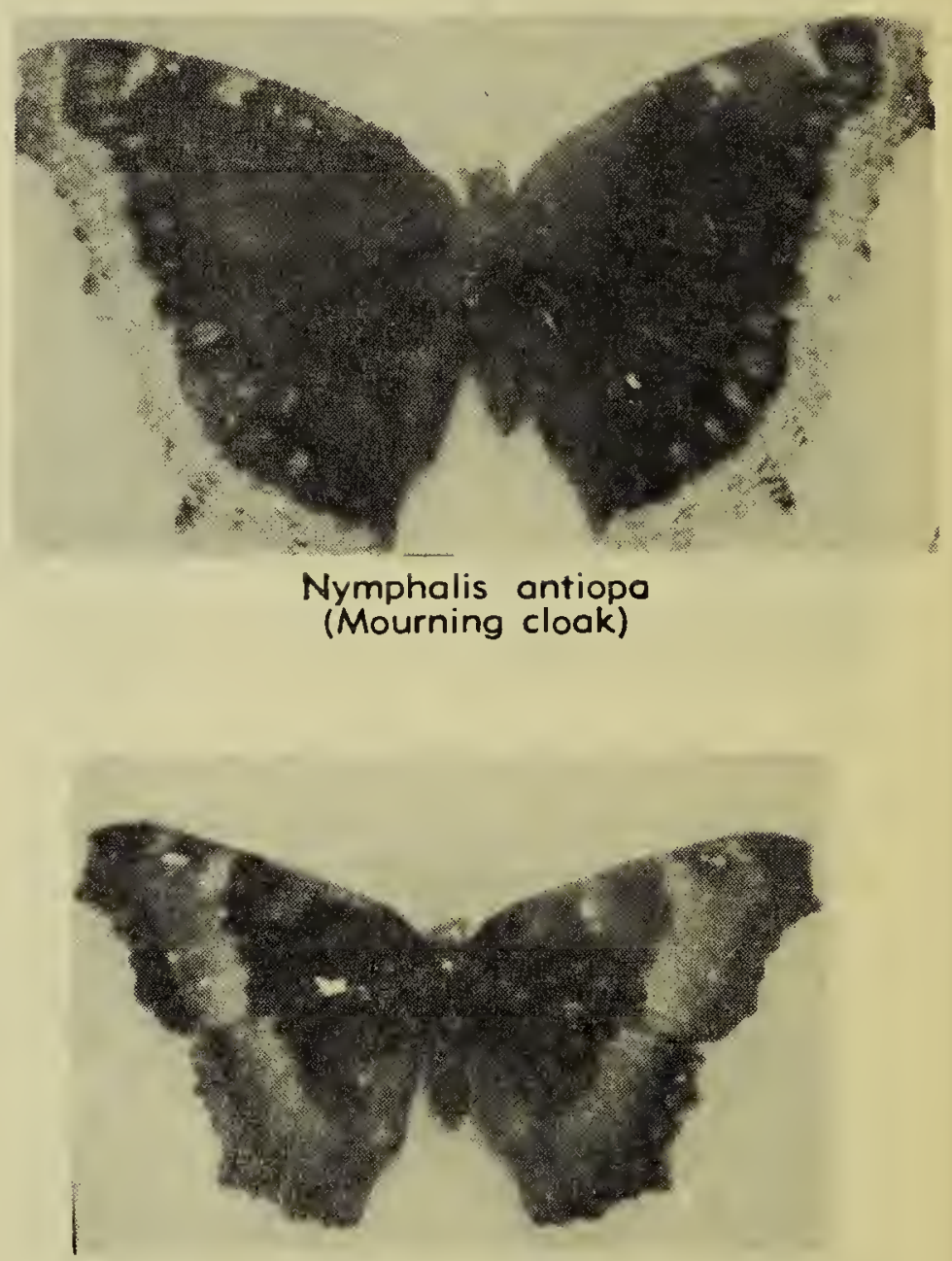

Nymphalis milberti (Milbert's Tortoise-shell)

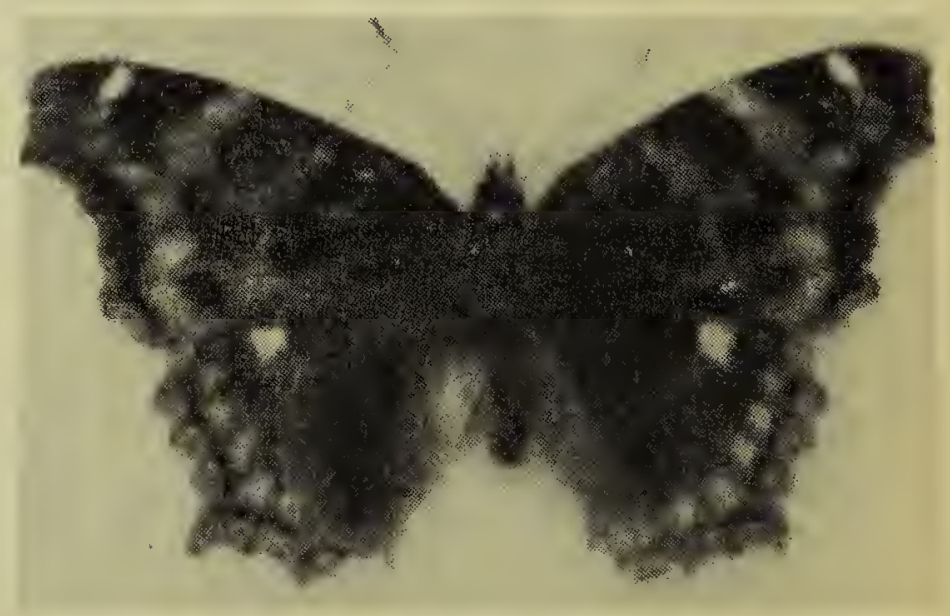

Nymphalis j-album

(Compton Tortoise-shell-found hibernating in a shack south of Dillabough, Dec. 19, 1953) 


\section{CALIFORNIA TORTOISE-SHELL Nymphalis californica}

The general range of this species is from California, north to southern British Columbia and Alberta. The larvae feed on plants of the genus Ceanothus, of the Buckthorn Family. Since they only occasionally feed on other trees and shrubs, they ordinarily do not occur in Saskatchewan. Any found here are probably windblown. We have taken them twice in the Somme district. It has also been taken at Lloydminster and at Miniota, Manitoba.

The color of this butterfly is yellow-orange, mottled with black. The wing expanse is about two inches.

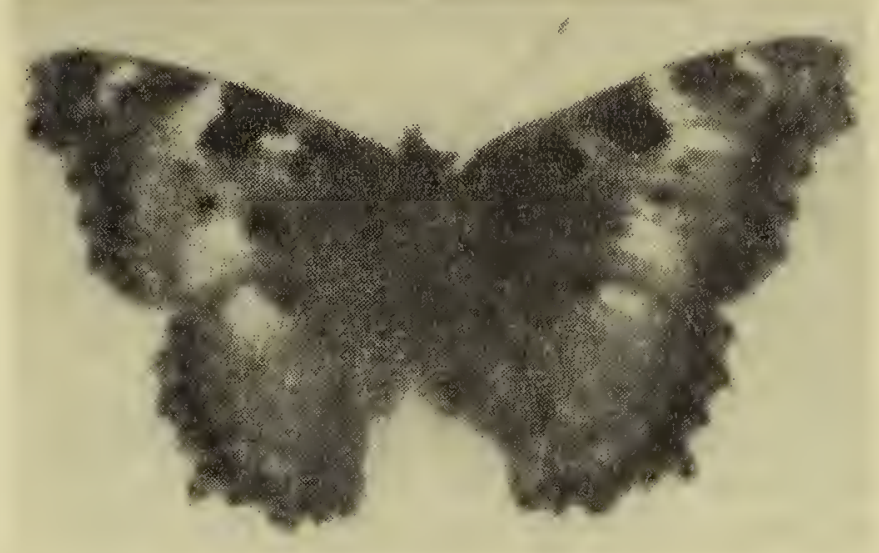

Nymphalis californica

(California Tortoise-shell-taken mid-September, 1952)

\section{Interested In Stone Age Relics}

George Marriott, Bateman, Sask.

Living conditions have changed a lot since I homesteaded here as one of the first settlers in 1908, complete with oxen, hand plows and sod shacks, 40 miles from town, and every other modern inconvenience.

While I am interested in birds my main weakness is Stone Age Relics, of which I have a very nice little collection. Now that the "Spade and Screen" is no more, I hope to see more articles in the "Blue Jay" along that line.

\section{Early Minnesota Find} Photo by Fred Robinson, Regina

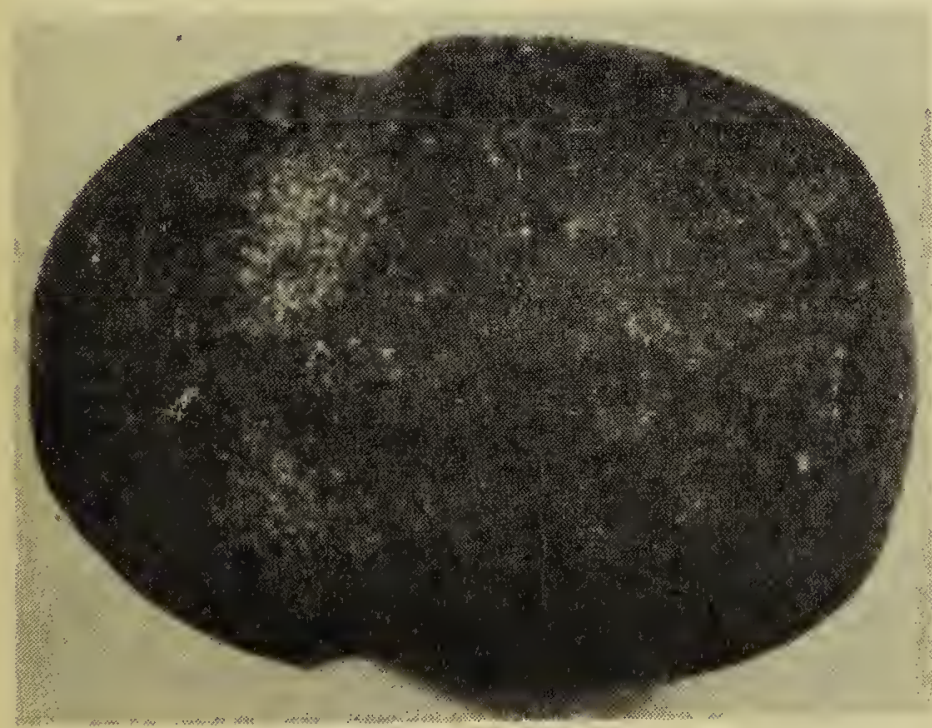

Mr. J. Turnquist of Wallwort, Saskatchewan, sends in a report of a peculiar shaped stone hammer found many years ago in a lake in Minnesota. The stone hammer was picked up by Mr. Turnquist's father in 1910 . It was under two feet of water in a lake, which later became dry. It is quartsite and made with an incomplete ring or groove, similar to the one pictured on this page. The stone also showed effects of glacial wear or polish. It was difficult to tell whether the glacial wear was made after the groove had been put on or before. This made an interesting puzzle, because if the wear had been after fabrication by man, it would indicate great age.

\section{Lack Of Space}

It is with regret that, due to lack of space, we will be unable to publish some very interesting articles in this issue. Among these are, "All that remains of Fort Esperance" (1 page), by Cliff Shaw, Yorkton; "Sod Shacks, and a Glimpse inte the Past," by Isabelle Powell, Swift Current, (11/4 pages); "Ruins of R.N.W.M.P. Fort at Fort Qu'Appelle," by Mary F. Brennan, Leross ( $1 / 2$ page); "A Glance at Mosses," by Dr. Henry S. Conard, State University of Iowa (3 pages); "Mammals of the Transition Zone," by Frank Brazier, Regina (21/2 pages); "A List of Recent Scientific Papers," by Dr. Stuart Houston, Yorkton. We would like, in particular, to have published a story by Nellie Cameron, of Davidson, Sask., called "Paddy Boy of Ardagh" (3 pages), dealing in a beautiful and touching manner with the joyous life and sad death of a Cocker Spaniel. We hope that most of these will appear in future issues. 